OPEN ACCESS

Edited by:

Habibeh Khoshbouei,

University of Florida, United States

Reviewed by:

James Mark Otis,

Medical University of South Carolina,

United States

Devin Mueller,

Kent State University, United States

*Correspondence:

Yixiao LuO

luoyx@hunnu.edu.cn

Ewa Galaj

ewa.galaj@nih.gov

tThese authors have contributed equally to this work

Specialty section:

This article was submitted to

Neuropharmacology,

a section of the journal

Frontiers in Pharmacology

Received: 28 March 2021

Accepted: 07 May 2021

Published: 25 May 2021

Citation:

Chen L, Huang S, Yang C, Wu F,

Zheng Q, Yan H, Yan J, Luo Y and Galaj E (2021) Blockade of $\beta$-Adrenergic Receptors by

Propranolol Disrupts Reconsolidation of Drug Memory and Attenuates

Heroin Seeking.

Front. Pharmacol. 12:686845. doi: 10.3389/fphar.2021.686845

\section{Blockade of $\beta$-Adrenergic Receptors by Propranolol Disrupts Reconsolidation of Drug Memory and Attenuates Heroin Seeking}

\author{
Liangpei Chen ${ }^{1,2 \dagger}$, Shihao Huang ${ }^{1 \dagger}$, Chang Yang ${ }^{1 \dagger}$, Feilong Wu ${ }^{1}$, Qiuyao Zheng ${ }^{1}$, He $\mathrm{Yan}^{2}$, \\ Jie Yan ${ }^{2}$, Yixiao Luo ${ }^{1 *}$ and Ewa Galaj ${ }^{3 *}$ \\ ${ }^{1}$ Key Laboratory of Molecular Epidemiology of Hunan Province, School of Medicine, Hunan Normal University, Changsha, China, \\ ${ }^{2}$ Department of Forensic Science, School of Basic Medical Science, Central South University, Changsha, China, ${ }^{3}$ National \\ Institute on Drug Abuse, Molecular Targets and Medications Discovery Branch, Baltimore, MD, United States
}

Persistent traces of drug reward memories contribute to intense craving and often trigger relapse. A number of pharmacological interventions on drug-associated memories have shown significant benefits in relapse prevention at a preclinical level but their translational potential is limited due to deleterious side effects. Propranolol, a non-specific $\beta$-adrenergic receptors antagonist, is known for its ability to erase maladaptive memories associated with nicotine or cocaine in rodents and humans. However, little is known about its effect on reconsolidation of heroin memory and heroin seeking. In the present study, rats with a history of intravenous heroin self-administration received the propranolol treatment (10 mg/kg; i.p.) at different time windows with or without CS (conditioned stimulus) exposure. Our results showed that propranolol, when administered immediately after CS exposure but not $6 \mathrm{~h}$ later, can significantly attenuate cue-induced and drug-primed reinstatement of heroin seeking, suggesting that propranolol has the ability to disrupt heroin memory and reduce relapse. The propranolol treatment without retrieval of drug memory had no effect on subsequent reinstatement of heroin seeking, suggesting that its interfering effects are retrieval-dependent. Importantly, the effects of propranolol were long lasting as rats showed diminished drug seeking even 28 days after the treatment. Altogether, our study suggests that propranolol can interfere with reconsolidation of heroin memory and reduce subsequent drug seeking, making it an attractive therapeutic candidate for the treatment of opioid addiction and relapse prevention.

Keywords: drug memory, propranolol, reconsolidation, relapse, heroin, drug seeking, reinstatement

\section{INTRODUCTION}

Opioid use disorder, a chronic and recurrent brain disease (Leshner, 1997; Volkow et al., 2016), is considered as a maladaptive learning and memory disorder (Boening, 2001; Hyman, 2005). Much evidence shows that craving, compulsive opioid taking and seeking in human addicts are controlled by drug cues and opioid reward-associated memories (Childress et al., 1988; O'brien et al., 1992). In animal models of addiction, opiate-associated cues can reinforce intravenous drug selfadministration (Davis and Smith, 1976; Dymshitz and Lieblich, 1987; Di Ciano and Everitt, 2004), facilitate the acquisition of opiate tolerance (Siegel, 1975), enhance locomotor activity 
(Mucha et al., 1981), elicit conditioned place preference (Schenk et al., 1983; Bardo et al., 1984; Bardo and Neisewander, 1986) and reinstate drug seeking even after prolonged abstinence (Schuster and Woods, 1968; McFarland and Ettenberg, 1997; Peck and Ranaldi, 2014). Thus, the persistence of drug memories and difficulty in eliminating them are thought to be the root causes of compulsive drug use, seeking and relapse (Childress et al., 1986; Kelley, 2004; Torregrossa et al., 2011).

A number of pharmacological interventions on drugassociated memories have shown significant benefits in relapse prevention at a preclinical level but their translational potential is limited due to deleterious side effects that the amnestic agents produce (Lee et al., 2005; Milton et al., 2008a; Milton et al., 2008b; Taylor et al., 2009; Sanchez et al., 2010; Wells et al., 2013). Drug memories can become labile after retrieval (Lee, 2009; Phelps and Hofmann, 2019), and require protein synthesis to be re-stabilized. During this process, known as memory reconsolidation, labile drug memories can be manipulated by pharmacological agents such as U0126 (an inhibitor of the mitogen-activated protein kinase1/2) or anisomycin (a peptidyl transferase inhibitor), leading to a reduction in subsequent cocaine- or nicotineconditioned place preference (CPP) and drug seeking (Miller and Marshall, 2005; Lv et al., 2015; Sorg et al., 2015; Xue et al., 2017a). However, clinical applications of these pharmacological agents are fairly limited due to their side effects.

Propranolol, a non-specific $\beta$-adrenergic receptor ( $\beta$-AR) antagonist, appears to be a promising candidate. Emerging evidence from clinical and preclinical studies reveals that noradrenergic signaling plays a critical role in memory reconsolidation (Schwabe et al., 2012; Haubrich et al., 2020). Unlike U0126 or anisomycin, propranolol can be safely administered to humans and effectively reduce cocaine or nicotine craving in human population (Saladin et al., 2013). In animal models of drug abuse, propranolol attenuates cocaine, morphine and nicotine seeking CPP through disruption of the association between drug cues and drug rewarding effects (Bernardi et al., 2006; Robinson et al., 2011a; Xue et al., 2017b). However, to date, there is no direct evidence indicating that propranolol can reduce heroin craving and prevent relapse. Given that heroin addicts show abnormal functioning of alpha2-adrenoceptors in the brain (Meana et al., 2000) and that the noradrenergic system is involved in drug memory reconsolidation (Fricks-Gleason and Marshall, 2008; Otis et al., 2015), it is conceivable that propranolol might disrupt reconsolidation of heroin memory and attenuate craving for heroin. If so, one would expect that propranolol would diminish cue- and drug-induced reinstatement of heroin seeking. Thus, in this study, we assessed whether propranolol can interfere with memory reconsolidation when administered at different time windows with or without CS (conditioned stimulus) exposure and whether its effects on heroin seeking are long lasting.

\section{MATERIALS AND METHODS}

\section{Subjects}

Male Sprague Dawley rats (weighing 260-280 g on arrival) were housed in groups of five under a $12 \mathrm{~h}$ reversed light/dark cycle (lights off at 8:00 A.M. and lights on at 8:00 P.M.) in a climatecontrolled environment with a constant temperature $\left(23 \pm 2^{\circ} \mathrm{C}\right)$, humidity (approximately 60\%), and with free access to food and water. Prior to surgeries, rats were handled for $3 \mathrm{~min}$ per day for five consecutive days. Animal care and experimental procedures were conducted in accordance with the National Research Council and Hunan Province Guide for the Care and Use of Laboratory Animals. All experiments were approved by the Biomedical Ethics Committee for Animal Use and Protection of Hunan Normal University. The experiments were performed during animals' active cycle (i.e., dark cycle).

\section{Intravenous Surgery}

Rats (weighing $300-320 \mathrm{~g}$ at the time of surgery) were anesthetized with sodium pentobarbital $(60 \mathrm{mg} / \mathrm{kg}$, i.p.). Catheters were inserted into the right jugular vein with the tip terminating at the opening of the right atrium as described previously ( $\mathrm{Lu}$ et al., 2005; Ambroggi et al., 2008). The catheter was connected to a bent 22-gauge stainless steel connector mounted to the rat's skull using four stainless steel screws and dental acrylic. The intravenous catheters were kept patent by infusion of $0.1 \mathrm{ml}$ of heparinized saline (30 USP heparin/saline; Hospira) every 2 days. Before the start of experimentation rats were allowed to recover for 5-7 days.

\section{Behavioral Procedures}

\section{Intravenous Heroin Self-Administration Training}

The heroin self-administration training paradigm and conditions were adapted from our previous studies (Ye et al., 2017). Operant chambers (AniLab Software and Instruments, Ningbo, China) were equipped with two nosepoke operandi (AniLab Software and Instruments, Ningbo, China) located $5 \mathrm{~cm}$ above the floor and with light stimuli. Rats were trained to self-administer heroin intravenously $(0.05 \mathrm{mg} / \mathrm{kg} /$ infusion $)$ during three 1 -h daily training sessions separated by $5 \mathrm{~min}$ for 10 days. We used a fixed-ratio 1 (FR1) schedule of reinforcement with a 40-s time-out employed after each infusion. Briefly, rats were connected to a drug line consisting of a metal tether covering a polyethylene tubing which, through a fluid swivel (Instech, Plymouth Meeting, PA), was connected to a syringe pump loaded with a $10 \mathrm{ml}$ syringe. The session began with the illumination of a house light that remained on for the entire session. Nosepokes into the active operandum led to a delivery of intravenous heroin accompanied by presentation of a 5-s tone-light cue. Nosepokes into the inactive operandum were counted but had no consequences. The heroin self-administration procedure was used in all four experiments. We excluded a total of eight rats from the experiments: three rats due to catheter patency failure and five rats due to failure to acquire heroin self-administration.

\section{Nosepoke Extinction}

Following the drug self-administration phase, rats were subjected to the extinction training. During 3-h daily nosepoke extinction sessions (Experiments 1-4), nosepokes to either of the operandi had no programmed consequences (i.e., heroin infusion and conditioned tone-light cues were not delivered). Rats were subjected to the extinction training until the frequency of 
active nosepoke responding decreased below $20 \%$ of the average responding during the last three heroin self-administration sessions for at least two consecutive days.

\section{Reactivation of Heroin Memory}

A 15-min session to reactive heroin-associated memories commenced $24 \mathrm{~h}$ later after the last nosepoke extinction session (in Experiment 1, 2,4). The retrieval conditions were the same as during the heroin self-administration training except that active nosepokes were reinforced with drug cues but not heroin.

\section{Cue Extinction}

During 3-h daily cue extinction sessions (Experiments 1,3,4), the conditions were the same as during the heroin self-administration training, but no heroin infusions followed the delivery of cue (tone/light).

\section{Propranolol Treatment}

Rats were injected with saline or propranolol (i.p. $10 \mathrm{mg} / \mathrm{kg}$ ) immediately after the CS exposure (reactivation session) (Experiments 1, 2). In Experiment 3, rats received the propranolol or saline treatment without CS exposure and in Experiment 4, $6 \mathrm{~h}$ after the CS exposure rats received an intraperitoneal injection of propranolol or saline and were housed in their home cages until further testing.

\section{Cue-Induced Reinstatement of Drug Seeking (Experiments 1-4)}

Twenty-four hours after the propranolol or saline treatment (i.p.), rats were subjected to the reinstatement test induced by drug cues. The test condition was identical to that of heroin selfadministration training, with the exception that active nosepokes led to contingent presentations of the tone-light cue that had been previously paired with heroin and were not reinforced with heroin. The reinstatement test lasted $1 \mathrm{~h}$.

\section{Heroin-Induced Reinstatement of Drug Seeking (Experiments 1, 3, 4)}

Rats were injected with heroin $(0.25 \mathrm{mg} / \mathrm{kg}$, i.p. $) 5 \mathrm{~min}$ before being placed into the self-administration context. The test conditions were the same as that of the drug selfadministration training with the exception that active nosepokes were reinforced with drug cues but not heroin. The reinstatement test lasted $1 \mathrm{~h}$.

\section{Cue-Induced Reinstatement Test After Prolonged Withdrawal (Experiment 2)}

For the cue-induced reinstatement test after prolonged withdrawal, active and inactive operandum nosepokes were recorded for $1 \mathrm{~h}$ 28 days after the forced withdrawal. The testing conditions were the same as those during the cue-induced reinstatement test.
A

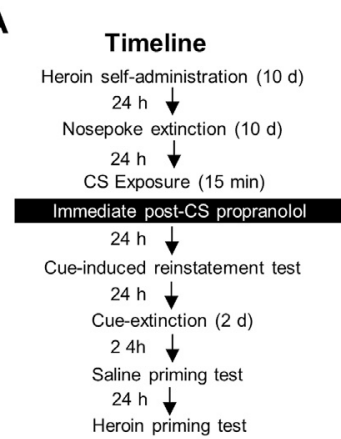

B

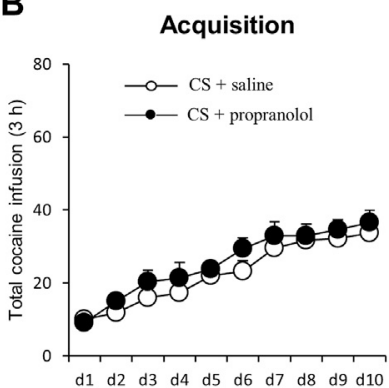

C

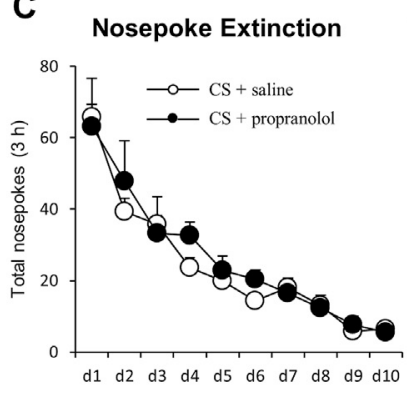

D

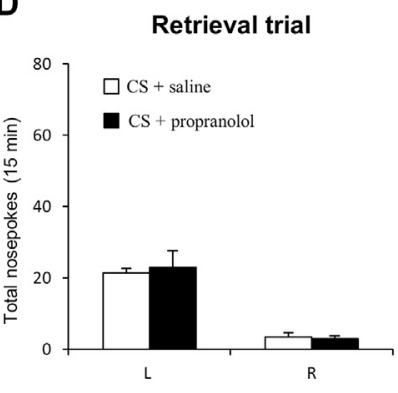

E

Cue induced reinstatement test

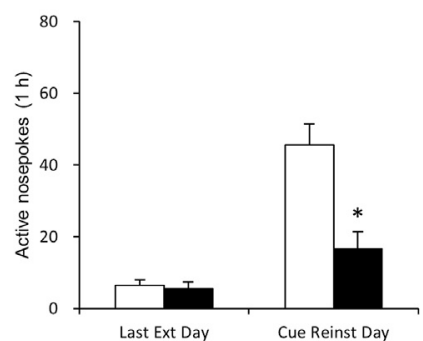

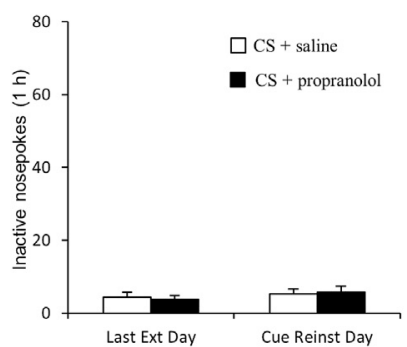

$\mathbf{F}$

Drug induced reinstatement test
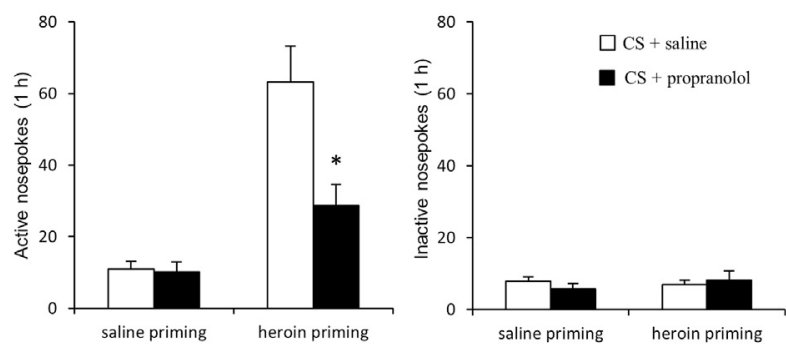

FIGURE 1 | Immediate post-CS reactivation propranolol treatment reduces subsequent cue-induced and heroin-primed reinstatement of heroin seeking. (A) Schematic representation of the experimental procedure. (B) Total number of heroin infusions across acquisition of heroin self-administration. (C) Total number of active nosepoke responses across extinction sessions. (D) Nosepoke responses during a reactivation trial. (E) Active (left) and inactive (right) nosepoke responses during the last extinction session and the cue-induced reinstatement test. (F) Active (left) and inactive (right) nosepoke responses during the saline- or heroin-primed reinstatement test. 


\section{Specific Experiments}

\section{Experiment 1A and B: The Effect of Immediate} Post-Conditioned Stimulus Reactivation Propranolol Treatment on Subsequent Cue-Induced and Drug-Primed Reinstatement of Heroin Seeking

Rats received heroin self-administration training for 10 days, followed by nosepoke extinction training for 10 consecutive days in the same operant chambers. Twenty-four hours after the last nosepoke extinction session, rats received a 15-min CS reactivation session induced by re-exposure to the heroin training context. Immediately after the CS reactivation session rats received an intraperitoneal injection of propranolol or physiological saline and $24 \mathrm{~h}$ later, a cue-induced reinstatement test was performed to verify whether the administration of propranolol immediately after retrieval of heroin cue memory destroys the expression of heroin cue memory in rats. Twenty-four hours after the cue-induced reinstatement test, rats received daily cue extinction sessions for two consecutive days. Twenty-four hours later, rats were tested for saline priming-induced reinstatement. Twenty-four hours after the saline priming-induced reinstatement, rats received heroin-induced reinstatement test. (see Figure 1A).

\section{Experiment 2: The Effect of Acute Treatment With Propranolol on Cue-Induced Reinstatement and Spontaneous Recovery 28 days Later}

In this experiment, rats received the propranolol treatment immediately after 15-min CS reactivation trial. Twenty-four hours later, a cue-induced reinstatement test occurred, followed by 28 days' abstinence and another cue-induced reinstatement test.

Experiments 3 A and B: The Effect of the Propranolol Treatment Without Conditioned Stimulus Reactivation on Subsequent Cue-Induced and Drug-Primed

\section{Reinstatement of Heroin Seeking}

The experimental procedure was identical to that of Experiment 1 , except that rats received an intraperitoneal injection of propranolol immediately after a 15-min no-reactivation session (see Figure 3A).

\section{Experiment $4 \mathrm{~A}$ and B: The Effect of Delayed} Post-Conditioned Stimulus Reactivation Propranolol Treatment on Subsequent Cue-Induced and Heroin Primed Reinstatement of Drug Seeking

The experimental procedure for Experiment 4 was identical to that of Experiment 1, except that the rats received an intraperitoneal injection of propranolol $6 \mathrm{~h}$ after a 15-min reactivation session (see Figure 4A).

\section{Statistical Analysis}

Experimental results were presented as mean \pm SEM and analyzed by GraphPad, v.8.0. The data were analyzed by repeated measures ANOVAs with between-subjects factor of treatment condition and within-subjects factor of test condition followed by Tukey's post-hoc test in each experiment (see results). $p<0.05$ were considered statistically significant.

\section{RESULTS}

\section{Experiment 1: Immediate Post-Conditioned Stimulus Reactivation Treatment With Propranolol Reduces Subsequent Reinstatement of Heroin Seeking}

We employed two groups of rats to test the effect of the postreactivation propranolol treatment on cue- and heroin-induced reinstatement of heroin seeking (Figure 1A). Groups-to-be treated with propranolol $(N=9)$ or saline $(N=9)$ did not differ during the acquisition of heroin self-administration, as indicated by the similar total numbers of heroin infusions [main effect of the training day: $\mathrm{F}_{(9,144)}=23.906, p<0.001$; main effect of the treatment condition: $\mathrm{F}_{(1,16)}=4.092, p=0.060$; interaction of training day $\times$ treatment condition: $\mathrm{F}_{(9,144)}=0.286, p=0.978$; Figure 1B]. No significant group differences were found during extinction, as revealed by the similar numbers of active and inactive nosepokes over 10-day extinction sessions [main effect of the extinction day: $\mathrm{F}_{(9,144)}=28.961, p<0.001$; main effect of the treatment condition: $\mathrm{F}_{(1,16)}=0.690, p=0.418$; interaction of extinction day $\times$ treatment condition: $\mathrm{F}_{(9,144)}=0.443, p=0.901$; Figure 1C]. For the reactivation test, there were no group difference of heroin infusions during the retrieval test [main effect of the different nosepokes: $\mathrm{F}_{(1,16)}=69.05, p<0.001$; main effect of the treatment condition: $\mathrm{F}_{(1,16)}=0.062, p=0.807$; interaction of different nosepokes $\times$ treatment condition: $\mathrm{F}_{(1,16)}=$ $0.214, p=0.650$; Figure 1D].

A two-way repeated-measures ANOVA for the cue-induced reinstatement data revealed a significant group difference in active nosepokes during the reinstatement test [main effect of the test condition: $\mathrm{F}_{(1,16)}=34.84, p<0.001$; main effect of the treatment condition: $\mathrm{F}_{(1,16)}=20.82, p<0.001$; interaction of test condition $\times$ treatment condition: $\mathrm{F}_{(1,16)}=10.97, p=0.004$; ]; Post-hoc shown that drug-seeking in the Retrieval + Propranolol group was significantly reduced as compared to the Retrieval + Saline group in the cueinduced reinstatement test $(p<0.05)$ (Figure 1E left column), but not in inactive side nosepokes [main effect of the test condition: $\mathrm{F}_{(1,16)}=1.083, p=0.314$; main effect of the treatment condition: $\mathrm{F}_{(1,16)}=0.008, p=0.931$; interaction of test condition $\times$ treatment condition: $\mathrm{F}_{(1,16)}=0.103, p=0.753$; Figure $1 \mathrm{E}$ right column]. In addition, there was a significant group difference in active nosepokes during the heroin-primed reinstatement test [main effect of test condition: $\mathrm{F}_{(1,16)}=$ 44.53, $p<0.001$; main effect of treatment condition: $\mathrm{F}_{(1,16)}$ $=8.31, p=0.011$; test condition interaction $\times$ treatment condition: $\left.\mathrm{F}_{(1,16)}=10.08, p=0.006\right]$; A Post-hoc test revealed that drug-seeking in the Retrieval + Propranolol group was significantly reduced compared to the Retrieval + Saline group in the priming-induced reinstatement test $(p<0.05)$ (Figure 1F left column), but not in inactive nosepokes [main effect of the test condition: $\mathrm{F}_{(1,16)}$ $=0.251, p=0.623$; main effect of the treatment condition: $\mathrm{F}_{(1,16)}=$ $0.058, p=0.813$; interaction of test condition $\times$ treatment condition: $\mathrm{F}$ $(1,16)=1.154, p=0.299$; Figure $1 F$ right column]. The results of this experiment indicate that intraperitoneal injection of propranolol immediately after the heroin cue reactivation suppresses cueinduced and heroin-primed reinstatement of heroin seeking. 


\section{Experiment 2: Immediate Propranolol Treatment Following Conditioned Stimulus Reactivation has Long Lasting Attenuating Effects on Heroin Seeking}

We aimed to assess the effect of immediate post-CS propranolol injection on cue-induced reinstatement of drug seeking as well as the long term effect (Figure 2A). During acquisition of heroin self-administration, there was no difference in the total numbers of infusion between the rats that would be infused with propranolol $(N=8)$ and those infused with saline $(N=9)$ [main effect of the training day: $\mathrm{F}_{(9,135)}=19.591, p<0.001$; main effect of the treatment condition: $\mathrm{F}_{(1,15)}=0.055, p=0.817$; interaction of training day $\times$ treatment condition: $\mathrm{F}_{(9,135)}=0.129$, $p=0.99$; Figure 2B]. Similarly, there was no significant group difference in the rate of extinction, as revealed by a two-way repeated-measures ANOVA [main effect of extinction day: $\mathrm{F}$ $(9,135)=40.177, p<0.001$; main effect of the treatment condition: $\mathrm{F}_{(1,15)}=0.507, p=0.488$; interaction of extinction day $\times$ treatment condition: $F_{(9,135)}=0.327, p=0.965$; Figure 2C]. For the reactivation test, there were no group difference of heroin infusions during the retrieval test [main effect of the different nosepokes: $\mathrm{F}_{(1,15)}=56.39, p<0.001$; main effect of the treatment condition: $\mathrm{F}_{(1,15)}=0.435, p=0.520$; interaction of test different nosepokes $\times$ treatment condition: $\mathrm{F}_{(1,15)}=0.124, p=0.730$; Figure 2D]. In line with the results from Experiment 1, the immediate post-CS propranolol treatment had significant effects on subsequent cue-induced reinstatement of active nosepoking (i.e., heroin seeking) [main effect of the test condition: $\mathrm{F}_{(1,15)}=$ $60.55, p<0.001$; main effect of the treatment condition: $\mathrm{F}_{(1,15)}=$ 26.58, $p<0.001$; interaction of test condition $\times$ treatment condition: $\left.\mathrm{F}_{(1,15)}=17.55, p<0.001\right]$; A Post-hoc test revealed that drug-seeking in the Retrieval + Propranolol group was significantly reduced compared to the Retrieval + Saline group in the cue-induced reinstatement test $(p<0.05)$ (Figure 2E left column), but not inactive nosepokes [main effect of the test condition: $\mathrm{F}_{(1,15)}=2.469, p=0.137$; main effect of the treatment condition: $\mathrm{F}_{(1,15)}=0.219, p=0.647$; interaction of test condition $\times$ treatment condition: $\mathrm{F}_{(1,15)}=0.159 ; p=0.696$; Figure $2 \mathrm{E}$ right column]. Furthermore, a repeated measures (rm)-ANOVA revealed a significant effect of active nosepokes during the cue-induced reinstatement test after prolonged withdrawal [ main effect of the test condition: $\mathrm{F}_{(1,15)}=100.9, p<0.001$; main effect of the treatment condition: $\mathrm{F}_{(1,15)}=25.38, p<$ 0.001 ; interaction of test condition $\times$ treatment condition: $\mathrm{F}$ $(1,15)=20.72, p<0.001]$; A post-hoc revealed that drugseeking in the Retrieval + Propranolol group was significantly reduced compared to the Retrieval + Saline group during the cue-induced reinstatement test after prolonged withdrawal $(p<0.05)$ (Figure 2F left column) but no significant difference in inactive nosepokes [ main effect of the test condition: $\mathrm{F}_{(1,15)}=3.431, p=0.084$; main effect of the treatment condition: $\mathrm{F}_{(1,15)}=0.293, p=0.597$; interaction of test condition $\times$ treatment condition: $\mathrm{F}_{(1,15)}=0.286, p=$ 0.600; Figure 2F right column]. Thus, these results suggest that the immediate post-CS propranolol treatment inhibits cue-indued heroin seeking and this effect lasts up to 28 days.

\section{Experiment 3: Intraperitoneal Propranolol Treatment Without Conditioned Stimulus Reactivation Has No Effect on Subsequent Reinstatement Heroin Seeking}

In this experiment, we examined whether the therapeutic effects of propranolol on subsequent heroin seeking is CS reactivation dependent. After heroin self-administration and extinction training, rats received an intraperitoneal injection of propranolol in the absence of a 15-min exposure to the drug cues/context (Figure 3A). No significant group differences were found in heroin self-administration [main effect of the training day: $F_{(9,108)}=31.568, p<0.001$; main effect of the treatment condition: $\mathrm{F}_{(1,12)}=0.054, p=0.820$; interaction of training day $\times$ treatment condition: $F_{(9,108)}=0.668, p=0.736$; Figure 3B] or nosepoke extinction rates [main effect of the extinction day: $F_{(9,108)}=26.749, p<0.001$; main effect of the treatment condition: $\mathrm{F}_{(1,12)}=0.001, p=0.972$; interaction of extinction day $\times$ treatment condition: $\mathrm{F}_{(9,108)}=0.384, p=0.941$; Figure 3C] between the rats that would be infused with propranolol $(N=7)$ and those infused with normal saline $(N=7)$. During the cue-induced reinstatement test, there were no significant difference in active nosepokes [main effect of the test condition: $\mathrm{F}_{(1,12)}=61.35, p<$ 0.001 ; main effect of the treatment condition: $\mathrm{F}_{(1,12)}=0.015, p=$ 0.903 ; interaction of test condition $\times$ treatment condition: $\mathrm{F}_{(1,12)}=$ $0.163, p=0.693$; Figure 3D, left column] and inactive nosepokes [main effect of the test condition: $\mathrm{F}_{(1,12)}=1.863, p=0.197$; main effect of the treatment condition: $F_{(1,12)}=0.288, p=0.602$; interaction of test condition $\times$ treatment condition: $F_{(1,12)}=$ 0.068, $p=0.799$; Figure 3D, right column] between the groups. During the heroin-primed reinstatement test, there were no significant difference in active nosepokes [main effect of test condition: $F_{(1,12)}=51.668, p<0.001$; main effect of treatment condition: $\mathrm{F}_{(1,12)}=0.001, p=0.976$; interaction of test condition $\times$ treatment condition: $F_{(1,12)}=0.123, p=0.732$; Figure $3 E$, left column] and inactive nosepokes [main effect of the test condition: $\mathrm{F}_{(1,12)}=2.555, p=0.136$; main effect of the treatment condition: $\mathrm{F}_{(1,12)}=0.134, p=0.721$; interaction of test condition $\times$ treatment condition: $\mathrm{F}_{(1,12)}=0.399, p=0.539$; Figure $3 \mathrm{E}$, right column]. Overall, the results of this experiment indicate that the therapeutic effect of propranolol on heroin seeking depends on the reactivation of drug-related memory and that propranolol alone has no effect on the following cue-induced or heroin-primed reinstatement of heroin seeking.

\section{Experiment 4: $6 \mathrm{~h}$-Delayed Propranolol Treatment Following Conditioned Stimulus Reactivation has No Effect on Subsequent Reinstatement of Heroin Seeking}

Next, we examined whether propranolol administered beyond the sensitive time window of memory reconsolidation would attenuate subsequent heroin seeking (Figure 4A). Groups did not differ in the acquisition of heroin self-administration [propranolol $(N=7) v s$. vehicle $(N=7)]$, as indicated by similar total numbers of heroin infusions [main effect of the training day: $\mathrm{F}_{(9,108)}=21.629, p<0.001$; main effect of treatment 

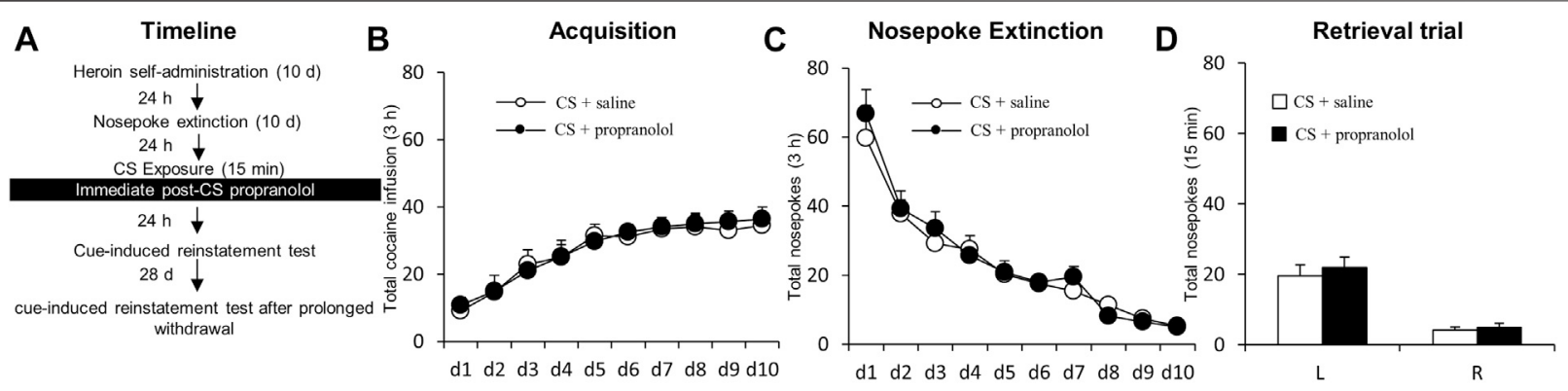

E

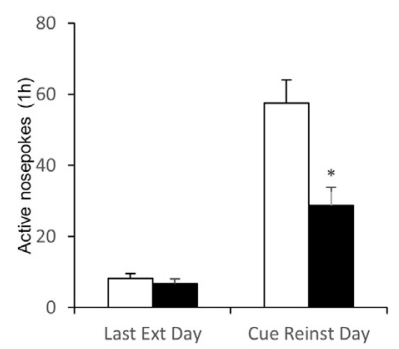

Cue induced reinstatement test

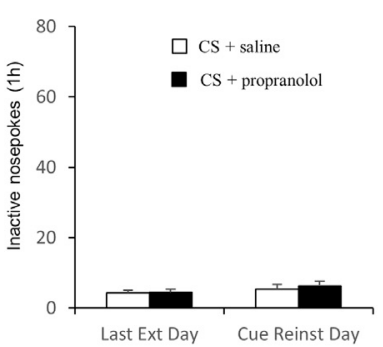

$\mathbf{F}$

cue-induced reinstatement test after prolonged withdrawal
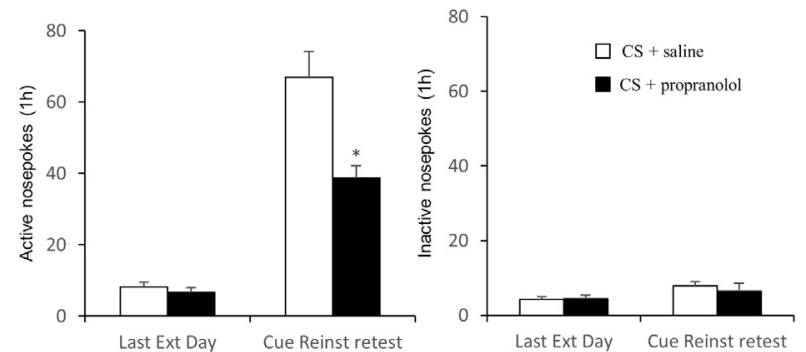

FIGURE 2 | Propranolol treatment immediately after CS reactivation attenuates subsequent and post-abstinence cue-induced reinstatement of heroin seeking. (A) Schematic representation of the experimental procedure. (B) Total number of infusions across heroin self-administration sessions. (C) Total number of active nosepoke responses across extinction sessions. (D) Nosepoke responses during a reactivation trial. (E) Active (left) and inactive (right) nosepokes during the last extinction session and cue-induced reinstatement test. (F) Active (left) and inactive (right) nosepokes during the last extinction session and cue-induced reinstatement test after prolonged withdrawal (after 28 days of abstinence).

condition: $\mathrm{F}_{(1,12)}=0.004, p=0.948$; training day interaction $\times$ treatment condition: $F_{(9,108)}=0.278, p=0.979$; Figure $\left.4 B\right]$. Additionally, there was no significant difference in nosepoke extinction rates as revealed by the similar numbers of active and inactive nosepokes across the extinction sessions [main effect of the extinction day: $\mathrm{F}_{(9,108)}=26.219, p<0.001$; main effect of the treatment condition: $\mathrm{F}_{(1,12)}=0.158, p=0.696$; interaction of extinction day $\times$ treatment condition: $\mathrm{F}_{(9,108)}=0.664, p=0.740$; Figure 4C]. During the reactivation test, there were no group difference of heroin infusions [main effect of the different nosepokes: $\mathrm{F}_{(1,12)}=57.17, p<0.001$; main effect of the treatment condition: $\mathrm{F}_{(1,12)}=0.007, p=0.937$; interaction of different nosepokes $\times$ treatment condition: $\mathrm{F}_{(1,12)}=0.295, p=$ 0.597; Figure 4D]. Also, no significant difference was observed in active nosepokes during a cue-induced reinstatement test [main effect of the test condition: $\mathrm{F}_{(1,12)}=113.6, p<0.001$; main effect of the treatment condition: $\mathrm{F}_{(1,12)}=0.102, p=0.755$; interaction of test condition $\times$ treatment condition: $\mathrm{F}_{(1,12)}=0.078, p=0.785$; Figure 4E, left column], as well as inactive nosepokes [main effect of test condition: $F_{(1,12)}=0.766, p=0.399$; main effect of treatment condition: $\mathrm{F}_{(1,12)}=0.144, p=0.711$; interaction of test condition $\times$ treatment condition: $F_{(1,12)} 0.035, p=0.854$; Figure 4E, right column]. There is no significant difference in heroin-primed reinstatement of heroin seeking (active nosepoke responses) [main effect of the test condition: $\mathrm{F}_{(1,12)}=44.114$, $p<0.001$; main effect of treatment condition: $\mathrm{F}_{(1,12)}=0.028, p=$ 0.869 ; interaction of test condition $\times$ treatment condition: $\mathrm{F}_{(1,12)}=$
0.071, $p=0.795]$; Figure $4 \mathrm{~F}$ left column], and inactive nosepokes [main effect of test condition: $\mathrm{F}_{(1,12)}=3.112, p=0.103$; main effect of treatment condition: $\mathrm{F}_{(1,12)}=0.074, p=0.790$; interaction of test condition $\times$ treatment condition: $\mathrm{F}_{(1,12)}=0.029, p=0.867$; Figure 4F right column]. The results of this experiment indicate that the effect of propranolol on reconsolidation of heroin reward memory is temporally specific.

\section{DISCUSSION}

Our study examined the effects of propranolol, a non-specific $\beta$-adrenoceptor antagonist, on reconsolidation of drug-associated memory using an intravenous heroin self-administration procedure. We found that systemic administration of propranolol immediately, but not $6 \mathrm{~h}$ after CS exposure significantly reduced cue-induced or drug-primed reinstatement of heroin seeking, suggesting that propranolol can disrupt heroin memory during memory reconsolidation. Furthermore, we found that the propranolol treatment without retrieval of drug memory had no effect on reinstatement of heroin drug seeking, suggesting that the effects of propranolol on reconsolidation of drug memory are retrieval-dependent. Finally, to test the long-lasting effect of propranolol on memory reconsolidation, the cue-induced reinstatement test was implemented again after 28 days' prolonged withdrawal. The results revealed that propranolol when administered 

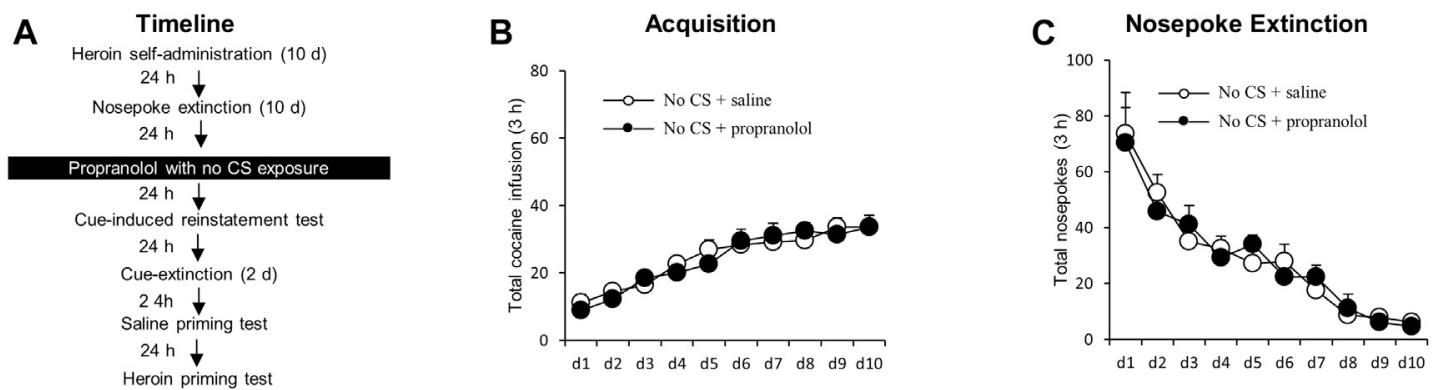

D

Cue induced reinstatement test

E

Drug induced reinstatement test
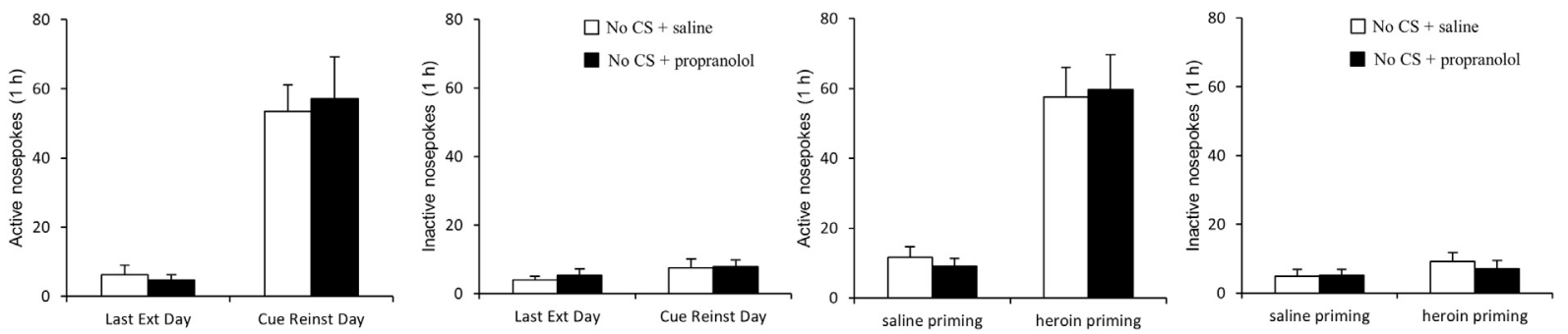

FIGURE 3 | Propranolol treatment without CS reactivation has no effect on subsequent cue-induced and heroin-primed reinstatement of heroin seeking. (A) Schematic representation of the experimental procedure. (B) Total number of infusions across acquisition of heroin self-administration. (C) Total number of active nosepoke responses across extinction sessions. (D) Active (left) and inactive (right) nosepoke responses during the last extinction session and cue-induced reinstatement test. (E) Active (left) and inactive (right) nosepoke responses during the saline-or heroin-primed reinstatement test.

immediately after CS reactivation reduced heroin seeking even 28 days later, indicating propranolol has potential to permanently reduce heroin seeking. Our findings are in line with previous studies demonstrating that memory reconsolidation can be disrupted after retrieval (Xue et al., 2012; Jian et al., 2014; Luo et al., 2015), and that propranolol can effectively do so when administered within a sensitive time window immediately and with memory retrieval (Przybyslawski et al., 1999; Diergaarde et al., 2006; Xue et al., 2017a). Altogether, the present results indicate that propranolol might be a vital pharmacotherapeutic in relapse prevention.

A large body of literature has shown that cocaine- or opioid CPP memory can be retrieved by drug-conditioned cues or drug itself (Robinson et al., 2011a; Lin et al., 2014; De Carvalho and Takahashi, 2017; Shen et al., 2020; Ding et al., 2021). In the present study, we found that $15 \mathrm{~min}$-CS exposure was sufficient to retrieve consolidated reward memory. Propranolol when employed as a potent amnestic agent, can interfere with drug memory and impair reinstatement of cocaine, nicotine or opioid CPP (Fricks-Gleason and Marshall, 2008; Otis and Mueller, 2011; Robinson et al., 2011b; Xue et al., 2017a) or spontaneous recovery through its antagonistic action on beta-noradrenergic receptors. In the present study we have demonstrated that propranolol can interfere with heroin seeking and relapse by disrupting drug memory during retrieval. However, when implemented with a delay, $6 \mathrm{~h}$ after CS exposure, it had no significant therapeutic benefits. Notably, substantial evidence from preclinical studies has shown that drug memories are labile and vulnerable for modification during a putative time window of memory reconsolidation. During memory reconsolidation new proteins are synthesized shortly after memory retrieval and potent protein synthesis inhibitors (e.g., anisomycin) or other agents (e.g., barberine, sulfur dioxide, rapamycin, cannabidiol) can disrupt this process producing long-term effects on drug seeking and relapse (Fuchs et al., 2010; Wells et al., 2011; Wu et al., 2013; Lin et al., 2014; Carvalho and Takahashi, 2016; Shen et al., 2020; Ding et al., 2021).

In this study, cue-induced and drug-primed reinstatement of heroin seeking was impaired by non-specific $\beta$-blocker propranolol when administered immediately after CS-retrieval, but not after a 6 hour-delay or without CS reactivation, indicating that the propranolol intervention with memory reconsolidation and relapse requires both temporal specificity and CS retrieval. We also demonstrated that the effects of post CS retrieval propranolol on heroin seeking are long lasting, suggesting relatively permanent interference with drug memory. Indeed, preclinical and clinical studies have demonstrated that propranolol has the ability to erase maladaptive memories associated with nicotine, cocaine, heroin or fear (FricksGleason and Marshall, 2008; Zhao et al., 2011; Xue et al., 2017b; Deng et al., 2020). Thus, there is compelling evidence suggesting that propranolol might have a therapeutic utility in clinical settings and be an attractive candidate for relapse prevention.

In the present study, propranolol that was delivered systematically produced robust effects on drug memory 


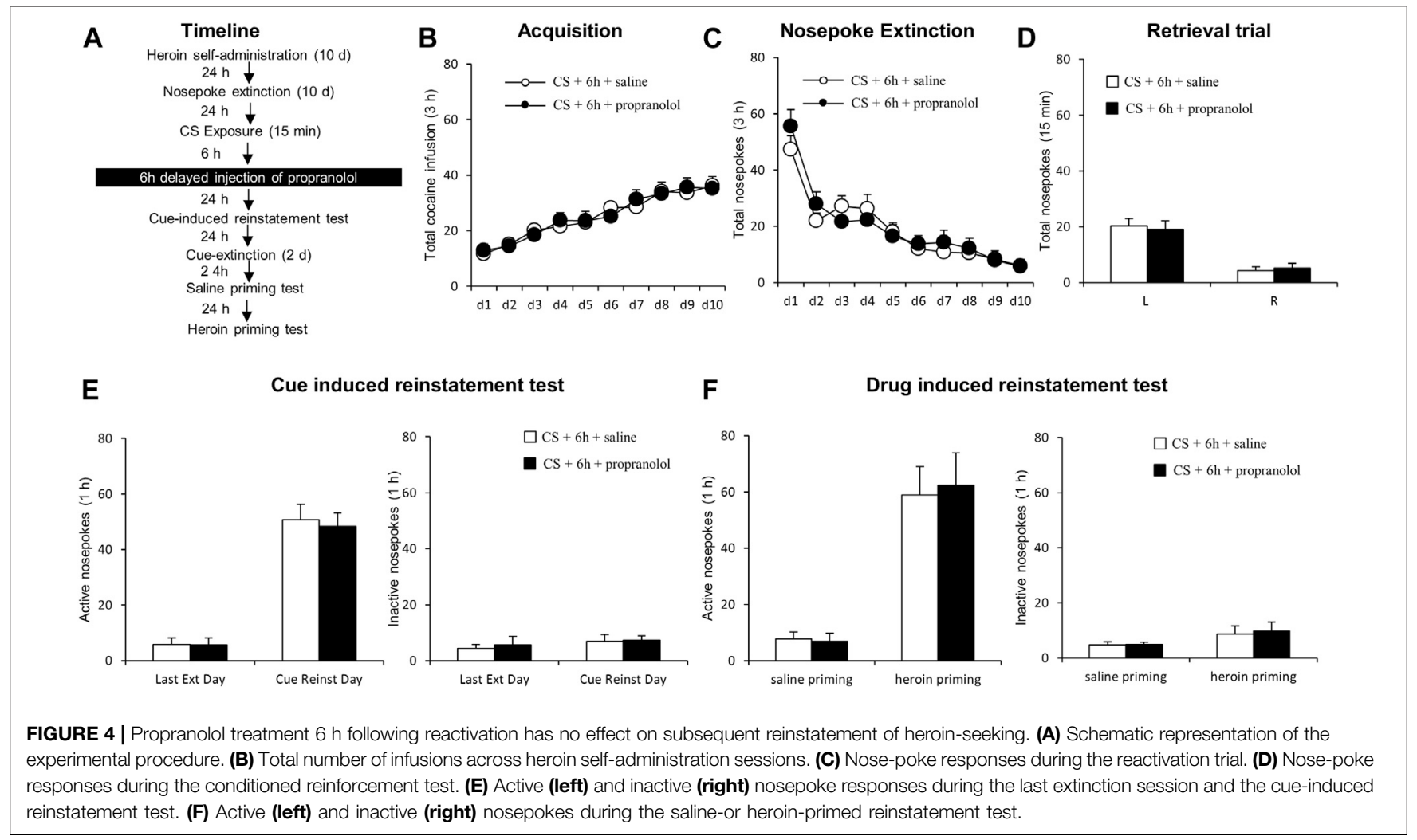

reconsolidation, suggesting that noradrenergic signaling likely controls drug memory reconsolidation. However, the precise noradrenergic mechanisms and neural circuit involved in heroin memory reconsolidation are yet to be determined. One potential target is the amygdala, a brain region involved in associative learning between environment cues and appetitive stimuli (Janak and Tye, 2015). Previous studies revealed that the basolateral amygdala receives the noradrenergic inputs from the nucleus tractus solitarius and locus coeruleus, which are known for their role in memory consolidation and reconsolidation. The amygdala output neurons project to the nucleus accumbens and this pathway is deemed for its critical role in cue-induced drug seeking and drug memory reconsolidation (Otis et al., 2015). In the follow-up studies we plan to systematically identify the neuronal circuitry underlying the noradrenergic signaling involved in drug memory reconsolidation. We intend to target the amygdala and identify its noradrenergic afferents (and its efferents) involved in the process of heroin memory reconsolidation.

Propranolol crosses the blood-brain barrier and targets the $\beta$-ARs through noradrenergic signaling system (Pardridge et al., 1983; Westfall and Westfall, 2006); the system is important for memory reconsolidation (Otis et al., 2015). Activation of $\beta$-ARs is known to increase neuronal excitability and contribute to synaptic plasticity of the glutamatergic system (Otis et al., 2013; Otis and Mueller, 2017). Thus, neuroplasticity induced by activation of $\beta$-ARs is thought to allow drug cues to drive compulsive drug taking and seeking. During memory reconsolidation after CS exposure, reactivated memory comes back to a stable state to be persistently stored, leading to permanent synaptic plasticity (Bonin and De Koninck, 2015; Chu et al., 2019). Propranolol by blocking $\beta$ noradrenergic receptors appears to take part in memory reconsolidation by interfering with synaptic plasticity. However, specific effects of propranolol on molecules and cellular processes within the noradrenergic system during memory reconsolidation remain to be elucidated.

In the present study, we used an intravenous drug selfadministration procedure, which more closely mimics drug abuse in humans (Spealman and Goldberg, 1978; Schindler et al., 2002). We believe that in contrast to a traditional conditioned place preference (CPP) paradigm (Sanchis-Segura and Spanagel, 2006; Tzschentke, 2007), this procedure is more appropriate to study craving and relapse. In fact, in the CPP procedure animals experience drug effects in a passive way and their drug intake are not voluntary, whereas in human addict drug taking and seeking are voluntary and reinforced by drugs and drug cues. In other words, human responses to drugs are contingent on consequences. Therefore, the drug-selfadministration procedure more adequately reflects human addiction behaviors when combined with a retrieval trial, it can be used to study memory reconsolidation.

In summary, the present study introduced a potential procedure that combines voluntary drug taking and seeking with a retrieval trial to study the effects of pharmacological intervention on memory reconsolidation and subsequent cueand drug-induced drug seeking. We have demonstrated that in this paradigm, a non-selective $\beta$-Adrenoceptor receptor antagonist, when administered during a sensitive time window after retrieval, can disrupt memory reconsolidation and attenuate subsequent relapse. Overall, our findings suggest that propranolol 
might be a potential therapeutic candidate for relapse prevention to opioids and treatment of opioid addiction.

\section{DATA AVAILABILITY STATEMENT}

The raw data supporting the conclusions of this article will be made available by the authors, without undue reservation.

\section{ETHICS STATEMENT}

The animal study was reviewed and approved by the Biomedical Ethics Committee for Animal Use and Protection of Hunan Normal University.

\section{REFERENCES}

Ambroggi, F., Ishikawa, A., Fields, H. L., and Nicola, S. M. (2008). Basolateral amygdala neurons facilitate reward-seeking behavior by exciting nucleus accumbens neurons. Neuron 59, 648-661. doi:10.1016/j.neuron.2008. 07.004

Bardo, M. T., Miller, J. S., and Neisewander, J. L. (1984). Conditioned place preference with morphine: the effect of extinction training on the reinforcing CR. Pharmacology Biochemistry and Behavior 21, 545-549. doi:10.1016/s00913057(84)80037-4

Bardo, M. T., and Neisewander, J. L. (1986). Single-trial conditioned place preference using intravenous morphine. Pharmacology Biochemistry and Behavior 25, 1101-1105. doi:10.1016/0091-3057(86)90092-4

Bernardi, R. E., Lattal, K. M., and Berger, S. P. (2006). Postretrieval propranolol disrupts a cocaine conditioned place preference. Neuroreport 17, 1443-1447. doi:10.1097/01.wnr.0000233098.20655.26

Boening, J. A. L. (2001). Neurobiology of an addiction memory. Journal of Neural Transmission 108, 755-765. doi:10.1007/s007020170050

Bonin, R. P., and De Koninck, Y. (2015). Reconsolidation and the regulation of plasticity: moving beyond memory. Trends in neurosciences 38, 336-344. doi:10.1016/j.tins.2015.04.007

Carvalho, C.D., and Takahashi, R.N. (2016). Cannabidiol disrupts the reconsolidation of contextual drug-associated memories in Wistar rats. Addiction Biology.n/a-. doi:10.1111/adb. 12366

Childress, AR, Mclellan, AT, Ehrman, R, and O'brien, CP (1988). Classically conditioned responses in opioid and cocaine dependence: a role in relapse? NIDA Res Monogr 84, 25-43.

Childress, A. R., Mclellan, A. T., and O'Brien, C. P. (1986). Role of conditioning factors in the development of drug dependence. Psychiatric Clinics of North America 9, 413-425. doi:10.1016/s0193-953x(18)30603-8

Chu, C., Murdock, M. H., Jing, D., Won, T. H., Chung, H., Kressel, A. M., et al. (2019). The microbiota regulate neuronal function and fear extinction learning. Nature 574, 543-548. doi:10.1038/s41586-019-1644-y

Davis, WM, and Smith, SG (1976). Role of conditioned reinforcers in the initiation, maintenance and extinction of drug-seeking behavior. Pavlov J Biol Sci. 11, 222-36. doi:10.1007/BF03000316

De Carvalho, C. R., and Takahashi, R. N. (2017). Cannabidiol disrupts the reconsolidation of contextual drug-associated memories in Wistar rats. Addiction Biology 22, 742-751. doi:10.1111/adb.12366

Deng, J., Shi, L., Yuan, K., Yao, P., Chen, S., Que, J., et al. (2020). Propranololinduced inhibition of unconditioned stimulus-reactivated fear memory prevents the return of fear in humans. Translational psychiatry 10, 345. doi:10.1038/s41398-020-01023-w

Di Ciano, P., and Everitt, B. J. (2004). Conditioned reinforcing properties of stimuli paired with self-administered cocaine, heroin or sucrose: implications for the persistence of addictive behaviour. Neuropharmacology 47, 202-213. doi:10. 1016/j.neuropharm.2004.06.005

\section{AUTHOR CONTRIBUTIONS}

YL, LC and EG designed and supervised this study. LC, SH, FW, JY and HY carried out experiments. LC, SH prepared the manuscript. EG and CY organized the data. YL and CY contributed to manuscript revision with contributions from all of the other authors.

\section{FUNDING}

This work was supported in part by the Natural Science Foundation of China (No. 81771434), Outstanding Innovative Youth Training Program of Changsha (kq1905032). All of the authors declare no competing financial interests.

Diergaarde, L., Schoffelmeer, A. N. M., and De Vries, T. J. (2006). $\beta$-adrenoceptor mediated inhibition of long-term reward-related memory reconsolidation. Behavioural Brain Research 170, 333-336. doi:10.1016/j.bbr. 2006.02.014

Ding, R., Yang, Z., Zhang, Y., Gao, Y., Galaj, E., Shi, X., et al. (2021). Exogenous SO 2 donor treatment impairs reconsolidation of drug reward memory in mice. European Journal of Pharmacology. doi:10.1016/j.ejphar.2021.173911

Dymshitz, J., and Lieblich, I. (1987). Opiate reinforcement and naloxone aversion, as revealed by place preference paradigm, in two strains of rats. Psychopharmacology (Berl) 92, 473-477. doi:10.1007/bf00176481

Fricks-Gleason, A. N., and Marshall, J. F. (2008). Post-retrieval -adrenergic receptor blockade: Effects on extinction and reconsolidation of cocaine-cue memories. Learning \& Memory 15, 643-648. doi:10.1101/lm.1054608

Fuchs, RA, Bell, GH, Ramirez, DR, Eaddy, JL, and Su, ZI (2010). Basolateral amygdala involvement in memory reconsolidation processes that facilitate drug context-induced cocaine seeking. Eur J Neurosci. 30, 889-900. doi:10.1111/j. 1460-9568.2009.06888.x

Haubrich, J., Bernabo, M., and Nader, K. (2020). Noradrenergic projections from the locus coeruleus to the amygdala constrain fear memory reconsolidation. eLife 9. doi:10.7554/elife.57010

Hyman, S. E. (2005). Addiction: a disease of learning and memory. Ajp 162, 1414-1422. doi:10.1176/appi.ajp.162.8.1414

Janak, P. H., and Tye, K. M. (2015). From circuits to behaviour in the amygdala. Nature 517(7534), 284-292. doi:10.1038/nature14188

Jian, M., Luo, Y.-X., Xue, Y.-X., Han, Y., Shi, H.-S., Liu, J.-F., et al. (2014). eIF2 Dephosphorylation in Basolateral Amygdala Mediates Reconsolidation of Drug Memory. Journal of Neuroscience 34, 10010-10021. doi:10.1523/jneurosci. 0934-14.2014

Kelley, A. E. (2004). Memory and Addiction. Neuron 44, 161-179. doi:10.1016/j. neuron.2004.09.016

Lee, J. L. C. (2009). Reconsolidation: maintaining memory relevance. Trends in Neurosciences 32, 413-420. doi:10.1016/j.tins.2009.05.002

Lee, J. L. C., Di Ciano, P., Thomas, K. L., and Everitt, B. J. (2005). Disrupting reconsolidation of drug memories reduces cocaine-seeking behavior. Neuron 47, 795-801. doi:10.1016/j.neuron.2005.08.007

Leshner, A. I. (1997). Addiction is a brain disease, and it matters. Science 278, 45-47. doi:10.1126/science.278.5335.45

Lin, J, Liu, L, Wen, Q, Zheng, C, Gao, Y, Peng, S, et al. (2014). Rapamycin prevents drug seeking via disrupting reconsolidation of reward memory in rats. Int J Neuropsychopharmacol 17, 127-36. doi:10.1017/S1461145713001156

Lu, L., Hope, B. T., Dempsey, J., Liu, S. Y., Bossert, J. M., and Shaham, Y. (2005). Central amygdala ERK signaling pathway is critical to incubation of cocaine craving. Nat Neurosci. 8, 212-219. doi:10.1038/nn1383

Luo, Y.-X., Xue, Y.-X., Liu, J.-F., Shi, H.-S., Jian, M., Han, Y., et al. (2015). A novel UCS memory retrieval-extinction procedure to inhibit relapse to drug seeking. Nature communications 6, 7675. doi:10.1038/ncomms 8675

Lv, X.F., Sun, L.L., Cui, C.L., and Han, J.S. (2015). NAc Shell Arc/Arg3.1 Protein Mediates Reconsolidation of Morphine CPP by Increased GluR1 Cell Surface 
Expression: Activation of ERK-Coupled CREB is Required. Int J Neuropsychopharmacol 18 (9), pyv030. doi:10.1093/ijnp/pyv030

Mcfarland, K., and Ettenberg, A. (1997). Reinstatement of drug-seeking behavior produced by heroin-predictive environmental stimuli. Psychopharmacology 131, 86-92. doi:10.1007/s002130050269

Meana, J. J., González-Maeso, J., García-Sevilla, J. A., and Guimón, J. (2000). $\mu$-Opioid receptor and $\alpha 2$-adrenoceptor agonist stimulation of [35S]GTP $\gamma \mathrm{S}$ binding to G-proteins in postmortem brains of opioid addicts. Mol Psychiatry 5, 308-315. doi:10.1038/sj.mp.4000727

Miller, C. A., and Marshall, J. F. (2005). Molecular Substrates for Retrieval and Reconsolidation of Cocaine-Associated Contextual Memory. Neuron 47, 873-884. doi:10.1016/j.neuron.2005.08.006

Milton, A. L., Lee, J. L. C., Butler, V. J., Gardner, R., and Everitt, B. J. (2008a). Intraamygdala and systemic antagonism of NMDA receptors prevents the reconsolidation of drug-associated memory and impairs subsequently both novel and previously acquired drug-seeking behaviors. Journal of Neuroscience 28, 8230-8237. doi:10.1523/jneurosci.1723-08.2008

Milton, A. L., Lee, J. L. C., and Everitt, B. J. (2008b). Reconsolidation of appetitive memories for both natural and drug reinforcement is dependent on -adrenergic receptors. Learning \& Memory 15, 88-92. doi:10.1101/lm.825008

Mucha, R. F., Volkovskis, C., and Kalant, H. (1981). Conditioned increases in locomotor activity produced with morphine as an unconditioned stimulus, and the relation of conditioning to acute morphine effect and tolerance. Journal of Comparative and Physiological Psychology 95, 351-362. doi:10.1037/h0077778

O'brien, C. P., Childress, A. R., Mclellan, A. T., and Ehrman, R. (1992). Classical conditioning in drug-dependent humans. Ann NY Acad Sci. 654, 400-415. doi:10.1111/j.1749-6632.1992.tb25984.x

Otis, J. M., Dashew, K. B., and Mueller, D. (2013). Neurobiological dissociation of retrieval and reconsolidation of cocaine-associated memory. Journal of Neuroscience 33, 1271-1281. doi:10.1523/jneurosci.3463-12.2013

Otis, J. M., and Mueller, D. (2011). Inhibition of $\beta$-Adrenergic Receptors Induces a Persistent Deficit in Retrieval of a Cocaine-Associated Memory Providing Protection against Reinstatement. Neuropsychopharmacol 36, 1912-1920. doi:10.1038/npp.2011.77

Otis, J. M., and Mueller, D. (2017). Reversal of Cocaine-Associated Synaptic Plasticity in Medial Prefrontal Cortex Parallels Elimination of Memory Retrieval. Neuropsychopharmacol 42, 2000-2010. doi:10.1038/npp.2017.90

Otis, J. M., Werner, C. T., and Mueller, D. (2015)., 40. Neuropsychopharmacology. Noradrenergic regulation of fear and drug-associated memory reconsolidationNeuropsychopharmacol. official publication of the American College of Neuropsychopharmacology, 793-803. 40, doi:10.1038/npp.2014.243

Pardridge, W. M., Sakiyama, R., and Fierer, G. (1983). Transport of Propranolol and Lidocaine through the Rat Blood-Brain Barrier. PRIMARY ROLE OF GLOBULINBOUND DRUG. J. Clin. Invest. 71, 900-908. doi:10.1172/jci110844

Peck, J.A., and Ranaldi, R. (2014). Drug abstinence: Exploring animal models and behavioral treatment strategies. Psychopharmacology. doi:10.1007/s00213-0143517-2

Phelps, E. A., and Hofmann, S. G. (2019). Memory editing from science fiction to clinical practice. Nature 572, 43-50. doi:10.1038/s41586-019-1433-7

Przybyslawski, J., Roullet, P., and Sara, S. J. (1999). Attenuation of Emotional and Nonemotional Memories after their Reactivation: Role of $\beta$ Adrenergic Receptors. J. Neurosci. 19, 6623-6628. doi:10.1523/jneurosci.19-15-06623.1999

Robinson, M., Michael, A., and Franklin, K. (2011a). The Effect of Propranolol and Midazolam on the Reconsolidation of a Morphine Place Preference in Chronically Treated Rats. Frontiers in Behavioral Neuroscience 5, 42. doi:10. 3389/fnbeh.2011.00042

Robinson, M.J., Armson, M., and Franklin, K.B. (2011b). The effect of propranolol and midazolam on the reconsolidation of a morphine place preference in chronically treated rats. Front Behav Neurosci. 5, 42. doi:10.3389/fnbeh.2011. 00042

Saladin, M. E., Gray, K. M., Mcrae-Clark, A. L., Larowe, S. D., Yeatts, S. D., Baker, N. L., et al. (2013). A double blind, placebo-controlled study of the effects of post-retrieval propranolol on reconsolidation of memory for craving and cue reactivity in cocaine dependent humans. Psychopharmacology 226, 721-737. doi:10.1007/s00213-013-3039-3

Sanchez, H., Quinn, J. J., Torregrossa, M. M., and Taylor, J. R. (2010). Reconsolidation of a cocaine-associated stimulus requires amygdalar protein kinase A. Journal of Neuroscience 30, 4401-4407. doi:10.1523/jneurosci.3149-09.2010
Sanchis-Segura, C., and Spanagel, R. (2006). Behavioural assessment of drug reinforcement and addictive features in rodents: an overview. Addiction biology 11 (1), 2-38. doi:10.1111/j.1369-1600.2006.00012.x

Schenk, S., Hunt, T., Colle, L., and Amit, Z. (1983). Isolation versus grouped housing in rats: differential effects of low doses of heroin in the place preference paradigm. Life Sciences 32, 1129-1134. doi:10.1016/00243205(83)90118-2

Schindler, C. W., Panlilio, L. V., and Goldberg, S. R. (2002). Second-order schedules of drug self-administration in animals. Psychopharmacology 163 , 327-344. doi:10.1007/s00213-002-1157-4

Schuster, C. R., and Woods, J. H. (1968). The conditioned reinforcing effects of stimuli associated with morphine reinforcement. International Journal of the Addictions 3, 223-230. doi:10.3109/10826086809042897

Schwabe, L., Nader, K., Wolf, O. T., Beaudry, T., and Pruessner, J. C. (2012). Neural signature of reconsolidation impairments by propranolol in humans. Biological psychiatry 71, 380-386. doi:10.1016/j.biopsych.2011.10.028

Shen, X., Hui, R., Luo, Y., Yu, H., and Wen, D. (2020). Berberine Facilitates Extinction of Drug-Associated Behavior and Inhibits Reinstatement of Drug Seeking. Frontiers in Pharmacology 11, 476. doi:10.3389/fphar.2020. 00476

Siegel, S. (1975). Evidence from rats that morphine tolerance is a learned response. Journal of Comparative and Physiological Psychology 89, 498-506. doi: $10.1037 / \mathrm{h} 0077058$

Sorg, B. A., Todd, R. P., Slaker, M., and Churchill, L. (2015). Anisomycin in the medial prefrontal cortex reduces reconsolidation of cocaine-associated memories in the rat self-administration model. Neuropharmacology 92, 25-33. doi:10.1016/j.neuropharm.2014.12.029

Spealman, R. D., and Goldberg, S. R. (1978). Drug self-administration by laboratory animals: control by schedules of reinforcement. Annu. Rev. Pharmacol. Toxicol. 18, 313-339. doi:10.1146/annurev.pa.18.040178. 001525

Taylor, J. R., Olausson, P., Quinn, J. J., and Torregrossa, M. M. (2009). Targeting extinction and reconsolidation mechanisms to combat the impact of drug cues on addiction. Neuropharmacology 56 (Suppl 1), 186-195. doi:10.1016/j. neuropharm.2008.07.027

Torregrossa, M. M., Corlett, P. R., and Taylor, J. R. (2011). Aberrant learning and memory in addiction. Neurobiology of Learning and Memory 96, 609-623. doi:10.1016/j.nlm.2011.02.014

Tzschentke, T. M. (2007). Measuring reward with the conditioned place preference (CPP) paradigm: update of the last decade. Addiction biology 12, 227-462. doi:10.1111/j.1369-1600.2007.00070.x

Volkow, N. D., Koob, G. F., and Mclellan, A. T. (2016). Neurobiologic Advances from the Brain Disease Model of Addiction. NEngl J Med. 374, 363-371. doi:10. 1056/nejmra1511480

Wells, A. M., Arguello, A. A., Xie, X., Blanton, M. A., Lasseter, H. C., Reittinger, A. M., et al. (2013). Extracellular signal-regulated kinase in the basolateral amygdala, but not the nucleus accumbens core, is critical for contextresponse-cocaine memory reconsolidation in rats. Neuropsychopharmacol 38, 753-762. doi:10.1038/npp.2012.238

Wells, A. M., Lasseter, H. C., Xie, X., Cowhey, K. E., Reittinger, A. M., and Fuchs, R. A. (2011). Interaction between the basolateral amygdala and dorsal hippocampus is critical for cocaine memory reconsolidation and subsequent drug context-induced cocaine-seeking behavior in rats. Learning \& Memory 18, 693-702. doi:10.1101/lm.2273111

Westfall, T.C., and Westfall, D.P. (2006). Adrenergic agonists and antagonists. goodman \& gilmans the pharmacological basis of therapeutics.

Wu, Y, Li, Y, Yang, X, and Sui, N (2013). Differential effect of beta-adrenergic receptor antagonism in basolateral amygdala on reconsolidation of aversive and appetitive memories associated with morphine in rats. Addict Biol. 19, 5-15. doi:10.1111/j.1369-1600.2012.00443.x

Xue, Y.-X., Chen, Y.-Y., Zhang, L.-B., Zhang, L.-Q., Huang, G.-D., Sun, S.-C., et al. (2017a). Selective Inhibition of Amygdala Neuronal Ensembles Encoding Nicotine-Associated Memories Inhibits Nicotine Preference and Relapse. Biological Psychiatry 82, 781-793. doi:10.1016/j.biopsych.2017.04.017

Xue, Y.-X., Deng, J.-H., Chen, Y.-Y., Zhang, L.-B., Wu, P., Huang, G.-D., et al. (2017b). Effect of Selective Inhibition of Reactivated Nicotine-Associated Memories With Propranolol on Nicotine Craving. JAMA Psychiatry 74, 224-232. doi:10.1001/jamapsychiatry.2016.3907 
Xue, Y.-X., Luo, Y.-X., Wu, P., Shi, H.-S., Xue, L.-F., Chen, C., et al. (2012). A memory retrieval-extinction procedure to prevent drug craving and relapse. Science 336, 241-245. doi:10.1126/science.1215070

Ye, X., Kapeller-Libermann, D., Travaglia, A., Inda, M. C., and Alberini, C. M. (2017). Direct dorsal hippocampal-prelimbic cortex connections strengthen fear memories. Nat Neurosci. 20, 52-61. doi:10.1038/nn.4443

Zhao, L.-Y., Sun, L.-L., Shi, J., Li, P., Zhang, Y., and Lu, L. (2011). Effects of $\beta$-adrenergic receptor blockade on drug-related memory reconsolidation in abstinent heroin addicts. Drug and Alcohol Dependence 118, 224-229. doi:10. 1016/j.drugalcdep.2011.03.025
Conflict of Interest: The authors declare that the research was conducted in the absence of any commercial or financial relationships that could be construed as a potential conflict of interest.

Copyright $\odot 2021$ Chen, Huang, Yang, Wu, Zheng, Yan, Yan, Luo and Galaj. This is an open-access article distributed under the terms of the Creative Commons Attribution License (CC BY). The use, distribution or reproduction in other forums is permitted, provided the original author(s) and the copyright owner(s) are credited and that the original publication in this journal is cited, in accordance with accepted academic practice. No use, distribution or reproduction is permitted which does not comply with these terms. 